\title{
Are the Economically Optimal Harvesting Strategies of Uneven-Aged Pinus nigra Stands Always Sustainable and Stabilizing?
}

\section{Ignacio López-Torres ${ }^{1}{ }^{1 *}$, Sigfredo Ortuño-Pérez ${ }^{1}$, Fernando García-Robredo ${ }^{1}$, and} Carmen Fullana-Belda ${ }^{2}$

1 Universidad Politécnica de Madrid, ETSI de Montes, Ciudad Universitaria, 28040 Madrid, Spain;

E-Mails: sigfredo.ortuno@upm.es (S.O.-P.); fernando.garcia.robredo@upm.es (F.G.-R.)

2 Universidad Pontificia de Comillas, Alberto Aguilera, 23, 28015 Madrid, Spain;

E-Mail: c.fullana@cee.upcomillas.es

* Author to whom correspondence should be addressed; E-Mail: i.lopez@upm.es;

Tel.: +34-913-365-578; Fax: +34-915-439-557.

Received: 26 July 2013; in revised form: 22 September 2013 / Accepted: 30 September 2013 /

Published: 18 October 2013

\begin{abstract}
Traditional uneven-aged forest management seeks a balance between equilibrium stand structure and economic profitability, which often leads to harvesting strategies concentrated in the larger diameter classes. The sustainability (i.e., population persistence over time) and influence of such economically optimal strategies on the equilibrium position of a stand (given by the stable diameter distribution) have not been sufficiently investigated in prior forest literature. This article therefore proposes a discrete optimal control model to analyze the sustainability and stability of the economically optimal harvesting strategies of uneven-aged Pinus nigra stands. For this model, we rely on an objective function that integrates financial data of harvesting operations with a projection matrix model that can describe the population dynamics. The model solution reveals the optimal management schedules for a wide variety of scenarios. To measure the distance between the stable diameter distribution and the economically optimal harvesting strategy distribution, the model uses Keyfitz's delta, which returns high values for all the scenarios and, thus, suggests that those economically optimal harvesting strategies have an unstabilizing influence on the equilibrium positions. Moreover, the economically optimal harvesting strategies were unsustainable for all the scenarios.
\end{abstract}


Keywords: sustainability; stability; matrix model; discrete optimal control; maximizing strategy

\section{Introduction}

The goal of traditional uneven-aged forest management is a balance between equilibrium stand structure and economic profitability. In pursuing this balance, many harvesting strategies concentrate on the larger diameter classes. The sustainability (i.e., population persistence over time) and influence of such economically optimal strategies on the equilibrium position of a stand (given by the stable diameter distribution) have not been sufficiently investigated in prior forest literature. Using uneven-aged Pinus nigra stands as an example, we propose a discrete optimal control model that can assess whether the economically optimal harvesting strategies are sustainable or stabilizing. For this model, we rely on an objective function that integrates the financial data of harvesting operations with a matrix model that can describe the population dynamics.

Matrix models commonly serve to analyze the evolution, management and harvesting of tree populations [1-4]. Population growth rate in such models is the dominant eigenvalue, $\lambda_{0}$, of the transition matrix, A. According to asymptotic analysis (i.e., long-term behavior), we know that independent of the initial conditions, when $\lambda_{0}>1$, the total number of stems/ha of the tree population increases exponentially over time (without harvests), whereas when $\lambda_{0}<1$, the population decays until extinction, and when $\lambda_{0}=1$, the result is a stable distribution proportional to the right eigenvector, $W_{0}$, of the transition matrix that corresponds to $\lambda_{0}$. Gotelli [5] refers to the special case of the stable distribution when $\lambda_{0}=1$ as the "stationary distribution"; we consider a similar case in reference to the stable diameter distribution of the stand $W_{0}$.

This concept of stability relates closely to the concept of perturbation: A system is stable if it always returns to an equilibrium position following small perturbations (otherwise, the system is unstable). The stable distributions are closely dependent on recruitment, removal and stem migration throughout the diameter at breast height (dbh)-classes over time [6]. In fact, given the transition probabilities between diameter classes, for each pair $(R, G)$, where $G$ is the stand basal area and $R$ is the global amount of recruitment, the stable diameter distributions of managed uneven-aged Fagus sylvatica L. and Pinus nigra Arn. stands were calculated in [7-9] using a matrix model of stand diameter classes evolution. Those stable diameter distributions are associated with the "sustainable/stable" harvesting strategy [7,8], aimed at reaching in each harvest the proportions of stems/ha in each class corresponding to the stable diameter distribution of the stand, yielding the following "sustainable/stable" harvest rate:

$$
s=\frac{\lambda_{0}-1}{\lambda_{0}}
$$

for all the diameter classes and time steps. This rate corresponds to the case in which the right eigenvector associated with the dominant eigenvalue $\lambda=1$ of the transition matrix with harvests is $W_{0}$. 
Therefore, in the present study, we combine that matrix model to describe the population dynamics with an economic model (objective function) that summarizes the net present value (NPV) of all the management operations in a 70-year harvest cycle, which creates a discrete optimal control problem.

Optimal control theory enables the solution of a wide variety of dynamic problems, for which the evolution of the dynamic system (discrete or continuous) can be partially controlled by the agent's decision. In every moment, $t$, the system can be described by a set of state variables, $x_{k}(t)$ (e.g., stems/ha in diameter class $k$ at year $t$ ), so the planner chooses a specific set of control variables, $h_{k}(t)$ (e.g., the harvest rate in diameter class $k$ at year $t$ ). Different values for the control variables imply different paths in the phase space for the dynamic system, and the planner or manager must determine the control values that maximize the selected objective, according to the constraints of the problem.

Many authors have considered optimal control theory to model forest stands (e.g., continuous case, $[10,11]$; discrete case, [12-14]).

Thus, the main purpose of this study is to determine economically optimal harvesting strategies of uneven-aged Pinus nigra stands in the Spanish Iberian System and to analyze their sustainability and eventual destabilization (i.e., with the stable diameter distribution $W_{0}$ set as the initial condition, to discern if the introduction of an $N P V$ maximizing management strategy leads to distributions that move away from that equilibrium over time). Furthermore, we investigate the effects of diameter growth, stand density and recruitment on those strategies, considering a wide variety of typical management scenarios in the study area, obtained by combining three levels of diameter growth (Qualities I-III), three levels of stand basal area, $G=22,24$ and $26 \mathrm{~m}^{2} / \mathrm{ha}$, and three levels of global recruitment, $R=200,520$ and 840 stems/ha. Finally, an economic comparison has been performed between the economically optimal and the "sustainable/stable" harvesting strategies.

In the following sections, we describe the model and the estimates of the corresponding parameters. The general calculations, including regressions, were run using Maple version 16 [15], and the solutions to the optimization problems were derived from Solver Premium Platform version 7.1 [16] running under Excel 2010.

\section{Material and Methods}

\subsection{Population Dynamics}

The model for recruitment, harvesting and stem migration throughout the dbh classes over time is based on the model proposed by López et al. [7,8] for Fagus sylvatica L. and by López et al. [9] for Pinus nigra Arn. stands. In this case, the stands of the study area are located in the Spanish Iberian System, a mountain range extending about $400 \mathrm{~km}$ along the north-eastern edge of the central plateau, concentrating $60 \%$ of the area occupied by Pinus nigra in Spain [17]. The management of Pinus nigra stands in this area is currently based on the growth and yield tables for Pinus nigra Arn. in the Spanish Iberian System [18]. The data in these tables are classified according to growth level into five site qualities, of which only the first three have been selected as our data source. These three qualities (I, faster; II, medium; and III, slower diameter growth) were defined by the dominant heights reached at the reference age of 60 years (20,17 and $14 \mathrm{~m}$, respectively). 
The starting assumptions were as follows: (a) the forest is in a steady state; (b) the average diameter growth curves for Qualities I-III are defined by the Bertalanffy-Richards model; (c) within each diameter class, the probability distribution for the diameter of the trees is uniform (rectangular); and (d) harvesting operations occur at the beginning of every projection interval.

Harvesting operations in this study area generally took place every 10 years, so we adopted this period as the range of the projection intervals in the model. Considering this time period and the diameter growth functions corresponding to Qualities I-III, trees were grouped into $n$ diameter classes of equal width $w=6 \mathrm{~cm}:(0,6),(6,12),(12,18), \ldots,(30,36), \ldots$, with the last class being $(48 \rightarrow)$ (more than $48 \mathrm{~cm}$ ) for Quality I, $(42 \rightarrow)$ (more than $42 \mathrm{~cm}$ ) for Quality II and $(36, \rightarrow)$ (more than $36 \mathrm{~cm}$ ) for Quality III. Therefore, an individual tree in class $k$ can remain in class $k$ or progress to class $k+1$ during the projection interval $(t, t+10)$. The number of trees in each class changed in each projection interval, because some were harvested, some remained in the same diameter class and others grew past the boundary to the next diameter class. In such conditions, $p_{k}$ refers to the probability that an individual tree in class $k$ at time $t$ will appear in class $k+1$ at time $t+10$. The term, $r_{k}$, or the recruitment coefficient, is the number of offspring (stems/ha) living at time $t+10$ produced in the interval $(t, t+10)$ by an average tree in class $k$ at time $t$ (Similar to many standard size classified matrix models, we did not consider the smallest diameter class fertile.). The variable, $h_{k}(t)$, defines the proportion of harvested trees in class $k$ at year $t$, natural mortalities included. Finally, $x_{k}(t)$ and $x_{k}(t+10)$ describe the stem densities in class $k$ at the initial and final projection times. By analyzing the dynamics of the projections, we find that the model is described accurately by the matrix model:

$$
X(t+10)=A(I-H(t)) X(t)
$$

Where:

$$
A=\left(\begin{array}{cccccc}
1-p_{1} & r_{2} & r_{3} & \cdots & r_{n-1} & r_{n} \\
p_{1} & 1-p_{2} & 0 & \cdots & 0 & 0 \\
0 & p_{2} & 1-p_{3} & \cdots & 0 & 0 \\
\vdots & \vdots & \vdots & \ddots & \vdots & \vdots \\
0 & 0 & 0 & \cdots & 1-p_{n-1} & 0 \\
0 & 0 & 0 & \cdots & p_{n-1} & 1
\end{array}\right)
$$

$I$ is the identity matrix, $H(t)=\operatorname{diag}\left(h_{1}(t), h_{2}(t), \ldots, h_{n}(t)\right)$ is a diagonal matrix with the harvest rates $h_{k}(t)$ and $X(t)$ and $X(t+10)$ are column vectors indicating the stem densities at the initial and final times of projection, respectively.

\subsection{Optimization Model}

Since the main objective for the stands in the study area is the production of timber, we use, as the objective function of the optimization problem, the net present value of all the management operations over a time horizon of $T=70$ years, discounted to the beginning of the period, and from the landowner's perspective. The combination of this objective function with the population dynamics model produces a discrete optimal control problem, from which we have to determine control variables $h_{k}(t)$ that globally maximize the function: 


$$
N P V=\sum_{k=1}^{n} \sum_{t=0}^{T-10} x_{k}(t) h_{k}(t) v_{k}(t) \frac{1}{(1+i)^{t}}+\sum_{k=1}^{n} x_{k}(T) v_{k}(T) \frac{1}{(1+i)^{T}},
$$

where $x_{k}(t)$, or the state variables, represent the number of stems/ha in class $k$ at year $t, h_{k}(t)$, or the control variables, define the harvest rate in class $k$ at year $t, v_{k}(t)$ is the stumpage price that corresponds to class $k$ at year $t$ (euro/stem), $i$ is the discount rate and $T$ is the planning horizon in years (where $k=1$, $2, \ldots, n$ and $t=0,10,20, \ldots, T-10$ years). The first summation represents the income derived from the sale of timber, and the last is the final stocking value. It is well known that the NPV is a justifiable management objective for a single economic goal [19].

As commented on in the Introduction, the initial conditions must represent the stable diameter distributions of the stand or $X(0)=W_{0}$.

We also introduce the following constraints:

$$
m_{k} \leq h_{k}(t) \leq 1 \text { for } k=1,2, \ldots, n \text { and } t=0,10,20,30, \ldots, T-10,
$$

where $m_{k}$ is the natural mortality in class $k$.

By applying the "sustainable/stable" harvesting strategy to each scenario and setting $X(0)=W_{0}$ (stable diameter distribution) as the initial condition, the basal area of the stand continuously oscillates between the $G_{\min }$ (after harvesting) and $G_{\max }$ (before harvesting) values, and the stable diameter distribution is reached at each time step. Therefore, in order to compare the economically optimal and the "sustainable/stable" harvesting strategies, it is essential to assume an additional constraint to maintain the stand basal area throughout the harvest cycle within the range $G_{\min }-G_{\max }$ (where $G_{\max }=$ 22 for the $G=22 \mathrm{~m}^{2} /$ ha scenario, $G_{\max }=24$ for $G=24 \mathrm{~m}^{2} / \mathrm{ha}, G_{\max }=26$ for $G=26 \mathrm{~m}^{2} / \mathrm{ha}$ and $G_{\min }$ is the minimum basal area reached for each scenario under the "sustainable/stable" harvesting strategy) during the optimization process.

\subsection{Input Estimation}

\subsubsection{Transition Probabilities}

We calculated the transition probabilities by applying the method introduced by López et al. [9] considering that, given the basal area constraints and the low basal area scenarios of this study, stand density has small influence on diameter growth. Thus, the diameter growths were defined by the Bertalanffy-Richards function:

$$
D=f(t)=a\left(1-e^{-b t}\right)^{c}
$$

adjusted using regression analysis to data points $(t, D(t))$ in Gómez-Loranca's tables [18]. The main characteristics of these growth models for Qualities I-III are shown in Figure 1.

Using these diameter growth models, the transition probabilities from class $i$ to class $(i+1)$, or from interval $(6(i-1), 6 i)$ to interval $(6 i, 6(i+1))$, are given by:

$$
p_{i}=\frac{f\left(f^{-1}(6 i)+10\right)-6 i}{f\left(f^{-1}(6 i)+10\right)-f\left(f^{-1}(6(i-1))+10\right)}, \text { for } i=1,2,3,4, \ldots, n-1
$$

where $f^{-1}$, the inverse function of $f$ in (1), is defined by: 


$$
f^{-1}(D)=-\frac{1}{b} \log \left(1-\left(\frac{D}{a}\right)^{\frac{1}{c}}\right)
$$

(where $t$ is age in years and $D$ is dbh in $\mathrm{cm}$ ).

Figure 1. Diameter growth models: Quality I, $D=51.68\left(1-\mathrm{e}^{-0.015259 \cdot t}\right)^{1.255111}$; Quality II, $D=46.645633\left(1-\mathrm{e}^{-0.014318 \cdot t}\right)^{1.337062}$; and Quality III, $D=40.644134\left(1-\mathrm{e}^{-0.013838}\right)^{1.456382}$ (dbh, $D$, in cm and time $t$ in years). The coefficient of determination was always greater than 0.999 .

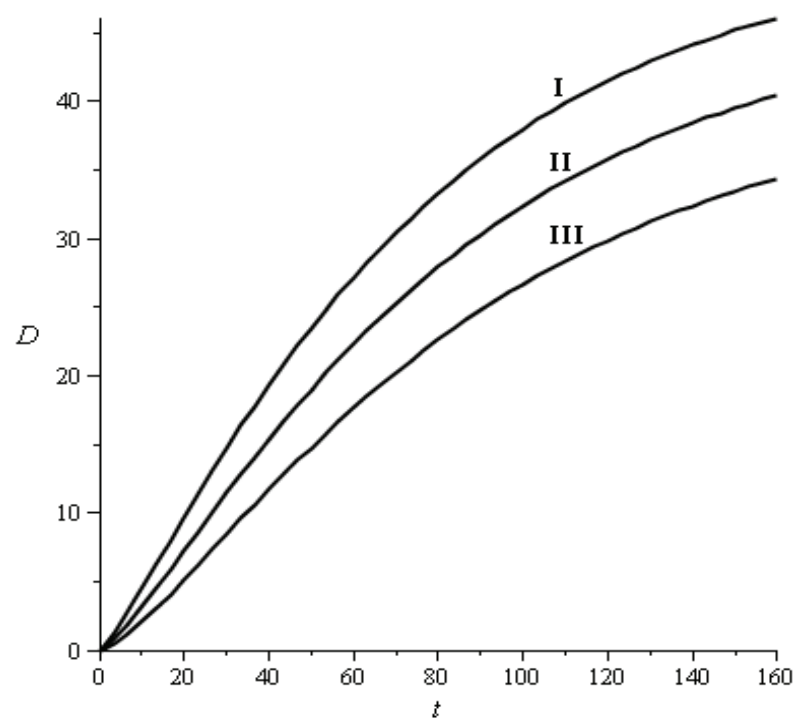

The above mentioned transition probability formula is a direct application of the one introduced by López et al. [7,8] for a Bertalanffy-Richards model. We provide the calculations for Qualities I-III in Table 1.

Table 1. Transition probabilities between diameter classes for each quality.

\begin{tabular}{cccc}
\hline & Quality I & Quality II & Quality III \\
\hline$(0,6) \rightarrow(6,12)$ & $p_{1}=0.7697$ & $p_{1}=0.5951$ & $p_{1}=0.4564$ \\
$(6,12) \rightarrow(12,18)$ & $p_{2}=0.8602$ & $p_{2}=0.6824$ & $p_{2}=0.5326$ \\
$(12,18) \rightarrow(18,24)$ & $p_{3}=0.7913$ & $p_{3}=0.6200$ & $p_{3}=0.4697$ \\
$(18,24) \rightarrow(24,30)$ & $p_{4}=0.6828$ & $p_{4}=0.5190$ & $p_{4}=0.3692$ \\
$(24,30) \rightarrow(30,36)$ & $p_{5}=0.5533$ & $p_{5}=0.3971$ & $p_{5}=0.2475$ \\
$(30,36) \rightarrow(36,42)$ & $p_{6}=0.4106$ & $p_{6}=0.2618$ & $p_{6}=0.1119$ \\
$(36,42) \rightarrow(42,48)$ & $p_{7}=0.2587$ & $p_{7}=0.1171$ & - \\
$(42,48) \rightarrow(48, \rightarrow)$ & $p_{8}=0.1000$ & - & - \\
\hline
\end{tabular}

According to the model assumptions and the methodology used, we had to consider that the same transition probability, $p_{k}$, applies to all the individuals in the same class $k$, where there might exist individuals under very different conditions (that is, the transition probability $p_{k}$ is a global property shared by all the individuals in the same class $k$, independently of their local conditions). We consider that the stratification into three quality classes must result in low variability around the mean $p_{k}$ values. 


\subsubsection{Recruitment and Basal Area}

Although Pinus nigra regenerates well under its own canopy [20,21] and recruitment may be very abundant even at high densities (more than 1,875 stems/ha during a regeneration in Pinus nigra stands where $G=51.96 \mathrm{~m}^{2} / \mathrm{ha}$, as described in [22]), there is a critical basal area for sufficient light transmittance for regeneration, that is, approximately $20-30 \mathrm{~m}^{2} /$ ha $[23,24]$. Therefore, we have considered in the calculations three levels of stand basal area in that range, $G=22,24$ and $26 \mathrm{~m}^{2} / \mathrm{ha}$. With these basal area values, we have assumed the same three levels of recruitment of our previous studies, $R=200$ (scarce recruitment), 520 (normal recruitment) and 840 (abundant recruitment) stems/ha. For these cases, similar to other matrix models for tree species [25], we attributed the global amount of recruitment $R$ entirely to the last diameter class $\left(r_{2}=r_{3}=\ldots=r_{n-1}=0 ; r_{n}=\frac{R}{x_{n}(0)}\right)$, which had no influence on the stable diameter distribution of the stand, which is established by transition probabilities, the global amount of recruitment and stand basal area [7].

\subsubsection{Natural Mortalities}

We estimated natural mortalities using previous studies. Specifically, Misir et al. [26] developed a logistic mortality model for Pinus nigra subsp. pallasiana in Turkey, and from the observed data, they estimated an overall annual mortality rate of $1.41 \%$, equivalent to a $13.24 \%$ mortality rate in a 10 -year period. Trasobares and Pukkala [27] studied Pinus nigra Arn. in north-eastern Spain and suggested natural mortality rates (including minimal intermediate thinning) of $2 \%$ for the $D>30 \mathrm{~cm}$ diameter classes.

We thus assumed the following 10-year individual tree constant mortality rates for each diameter class: $m_{1}=0.20, m_{2}=0.14, m_{3}=0.08, m_{4}=0.05, m_{5}=0.03$ and $m_{6}=m_{7}=\ldots=m_{n}=0.02$.

\subsubsection{Sustainable/Stable Harvesting Strategy: Stable Diameter Distribution}

As shown in the Introduction, the "sustainable/stable" harvesting strategy is aimed at reaching in each harvest the proportions of stems/ha in each class corresponding to the stable diameter distribution of the stand, yielding the following "sustainable/stable" harvest rate:

$$
s=\frac{\lambda_{0}-1}{\lambda_{0}}
$$

for all the diameter classes and time steps ( $s$ also includes the natural mortalities). This rate corresponds to the case in which the right eigenvector associated with the dominant eigenvalue $\lambda=1$ of the transition matrix with harvests is $W_{0}$.

As commented on in Section 2.2, by applying the "sustainable/stable" harvesting strategy to each scenario and setting $X(0)=W_{0}$ (stable diameter distribution) as the initial condition, the basal area of the stand continuously oscillates between the $G_{\min }$ (after harvesting) and $G_{\max }$ (before harvesting) values, and the stable diameter distribution is reached at each time step. The calculations for the 27 scenarios of this study, obtained by combining three levels of diameter growth with three levels of recruitment $\left(R=200,520\right.$ or 840 stems/ha) and three levels of stand basal area $\left(G=G_{\max }=22,24\right.$ or 
$26 \mathrm{~m}^{2} / \mathrm{ha}$ ) are shown in Table 2 along with the population growth rates, $\lambda_{0}$, the "sustainable/stable" harvest rates, $s$, and the minimum basal areas, $G_{\min }$.

The results obtained for $\lambda_{0}$ are within the intervals corresponding to other tree species. In this regard, Ramula and Lehtilä [28] and Zuidema [29] summarize the main characteristics of matrix models, for 35 woody species in the first case and for 37 plant species (13 of them trees) in the second. The variation range for $\lambda_{0}$ went from 0.977 to 1.589 in the first case and from 0.826 to 2.334 in the second. In natural forests, with light or no human intervention, $\lambda_{0}$ values are much lower, because of competition, which increases mortality rates and reduces transition probabilities, as well as recruitment. However, our results for $\lambda_{0}$, still within the intervals given in [28] and [29], were expected to be slightly high, due to the fact that natural mortalities were absorbed by the harvesting rate, $h$, not being incorporated into matrix $A$.

Table 2. Numerical values for $\lambda_{0}, s$, stable distributions and $N P V_{0}$ (R, recruitment; Q I-III, quality class I-III; $\lambda_{0}$, population growth rate without harvests; $s$, stable harvest rate; $G$, basal area in $\mathrm{m}^{2} /$ ha; Est. Dis., stable diameter distribution in stem/ha; $N P V_{0}$, net present value under the stable equilibrium in $€ /$ ha for $i=3 \%$ ).

\begin{tabular}{|c|c|c|c|c|c|}
\hline & & & $R=200$ stem $/ \mathrm{ha}$ & $R=520$ stem $/$ ha & $R=840$ stem $/ \mathrm{ha}$ \\
\hline \multirow{15}{*}{ Q I } & \multirow{5}{*}{$G=22$} & $\lambda_{0}$ & 1.305091 & 1.477671 & 1.594240 \\
\hline & & $s$ & 0.233770 & 0.323259 & 0.372742 \\
\hline & & $G_{\min }$ & 16.857068 & 14.888296 & 13.799677 \\
\hline & & $\begin{array}{l}\text { Est. } \\
\text { Dis. }\end{array}$ & $\begin{array}{l}{[186.1,122.9,96.4,77.2,} \\
61.4 .47 .5 .34 .6 .22 .1 .7 .2]\end{array}$ & $\begin{array}{c}{[416.9,239.8,162.6,110.9,} \\
73.4 .45 .7 .25 .5 .11 .4 .4]\end{array}$ & $\begin{array}{c}{[615.9,325.9,202.3,125.4,} \\
74.6 .41 .1 .19 .8 .74 .1 .2]\end{array}$ \\
\hline & & $N P V_{0}$ & $5,347.36$ & $6,118.03$ & $6,383.55$ \\
\hline & \multirow{5}{*}{$G=24$} & $\lambda_{0}$ & 1.292499 & 1.458959 & 1.571264 \\
\hline & & $s$ & 0.226305 & 0.314580 & 0.363570 \\
\hline & & $G_{\min }$ & 18.568685 & 16.450081 & 15.274322 \\
\hline & & $\begin{array}{l}\text { Est. } \\
\text { Dis. }\end{array}$ & $\begin{array}{l}{[188.3,125.7,99.8,81.0,} \\
65.4,51.4,38.3,25.3,8.6]\end{array}$ & $\begin{array}{c}{[423.2,246.9,169.9,117.8} \\
79.4,50.5,28.9,13.4,2.9]\end{array}$ & $\begin{array}{c}{[626.4,336.8,212.6,134.2} \\
81.5,45.9,22.7,8.8,1.5]\end{array}$ \\
\hline & & $N P V_{0}$ & $5,743.33$ & $6,611.13$ & $6,918.95$ \\
\hline & \multirow{5}{*}{$G=26$} & $\lambda_{0}$ & 1.281305 & 1.442342 & 1.550881 \\
\hline & & $s$ & 0.219546 & 0.306683 & 0.355205 \\
\hline & & $G_{\min }$ & 20.291808 & 18.026241 & 16.764668 \\
\hline & & $\begin{array}{l}\text { Est. } \\
\text { Dis. }\end{array}$ & $\begin{array}{l}{[190.3,128.3,102.9,84.5} \\
69.1,55.3,42.0,28.5,10.1]\end{array}$ & $\begin{array}{c}{[429.0,253.5,176.8,124.3} \\
85.3,55.3,32.4,15.5,3.5]\end{array}$ & $\begin{array}{c}{[636.1,347.0,222.4,142.6,} \\
88.2,50.8,25.7,10.2,1.9]\end{array}$ \\
\hline & & $N P V_{0}$ & $6,130.45$ & $7,096.29$ & $7,447.43$ \\
\hline \multirow{8}{*}{ Q II } & \multirow{6}{*}{$G=22$} & $\lambda_{0}$ & 1.262093 & 1.412527 & 1.514472 \\
\hline & & $s$ & 0.207665 & 0.292049 & 0.339704 \\
\hline & & $G_{\min }$ & 17.431369 & 15.574919 & 14.526515 \\
\hline & & $\begin{array}{l}\text { Est. } \\
\text { Dis. }\end{array}$ & $\begin{array}{c}{[233.3,147.0,113.7,90.3} \\
71.1,53.9,37.2,16.6]\end{array}$ & $\begin{array}{c}{[516.1,280.5,185.4,123.4} \\
79.1,46.6,23.0,6.5]\end{array}$ & $\begin{array}{c}{[757.0,376.4,226.4,135.8,} \\
77.3,39.6,16.4,3.7]\end{array}$ \\
\hline & & $N P V_{0}$ & $4,239.22$ & $4,986.61$ & $5,284.13$ \\
\hline & & $\lambda_{0}$ & 1.251140 & 1.396188 & 1.494358 \\
\hline & \multirow[t]{2}{*}{$G=24$} & $s$ & 0.200729 & 0.283764 & 0.330816 \\
\hline & & $G_{\min }$ & 19.182509 & 17.189656 & 16.060414 \\
\hline
\end{tabular}


Table 2. Cont.

\begin{tabular}{|c|c|c|c|c|c|}
\hline & & & $R=200$ stem $/$ ha & $R=520$ stem $/$ ha & $R=840$ stem $/$ ha \\
\hline \multirow{7}{*}{ Q II } & \multirow[t]{2}{*}{$G=24$} & $\begin{array}{l}\text { Est. } \\
\text { Dis. }\end{array}$ & $\begin{array}{c}{[236.3,150.7,118.0,95.0} \\
76.1,58.9,41.9,19.5]\end{array}$ & $\begin{array}{c}{[524.6,289.4,194.4,131.7} \\
86.1,52.0,26.5,7.8]\end{array}$ & $\begin{array}{c}{[771.0,389.9,238.8,146.1,} \\
85.0,44.7,19.1,4.5]\end{array}$ \\
\hline & & $N P V_{0}$ & $4,542.73$ & $5,373.95$ & $5,710.91$ \\
\hline & \multirow{5}{*}{$G=26$} & $\lambda_{0}$ & 1.241406 & 1.381684 & 1.476521 \\
\hline & & $s$ & 0.194462 & 0.276245 & 0.322732 \\
\hline & & $G_{\min }$ & 20.943989 & 18.817621 & 17.608961 \\
\hline & & $\begin{array}{l}\text { Est. } \\
\text { Dis. }\end{array}$ & $\begin{array}{c}{[239.1,154.0,122.0,99.5} \\
80.9,63.8,46.6,22.6]\end{array}$ & $\begin{array}{c}{[532.4,297.7,202.8,139.6} \\
93.0,57.4,30.1,9.2]\end{array}$ & $\begin{array}{c}{[783.9,402.5,250.5,156.0,} \\
92.7,49.8,22.0,5.4]\end{array}$ \\
\hline & & $N P V_{0}$ & $4,838.92$ & $5,754.14$ & $6,131.06$ \\
\hline \multirow{15}{*}{ Q III } & \multirow{5}{*}{$G=22$} & $\lambda_{0}$ & 1.220604 & 1.350816 & 1.439536 \\
\hline & & $s$ & 0.180733 & 0.259707 & 0.305332 \\
\hline & & $G_{\min }$ & 18.023866 & 16.286454 & 15.282699 \\
\hline & & $\begin{array}{l}\text { Est. } \\
\text { Dis. }\end{array}$ & $\begin{array}{c}{[295.4,179.0,138.1,110.0} \\
86.7,64.6,32.8]\end{array}$ & $\begin{array}{c}{[644.2,332.8,216.0,140.9} \\
87.0,46.5,14.8]\end{array}$ & $\begin{array}{c}{[937.6,440.2,257.8,149.7} \\
80.5,36.1,9.2]\end{array}$ \\
\hline & & $N P V_{0}$ & $3,202.56$ & $3,906.48$ & $4,224.82$ \\
\hline & \multirow{5}{*}{$G=24$} & $\lambda_{0}$ & 1.211164 & 1.336630 & 1.422004 \\
\hline & & $s$ & 0.174348 & 0.251850 & 0.296767 \\
\hline & & $G_{\min }$ & 19.815651 & 17.955611 & 16.877591 \\
\hline & & $\begin{array}{l}\text { Est. } \\
\text { Dis. }\end{array}$ & $\begin{array}{c}{[299.6,183.8,143.8,116.4} \\
93.7,71.8,38.0]\end{array}$ & $\begin{array}{c}{[655.8,344.3,227.4,151.3} \\
95.6,52.8,17.6]\end{array}$ & $\begin{array}{c}{[956.3,457.2,273.0,162.1,} \\
89.4,41.4,11.0]\end{array}$ \\
\hline & & $N P V_{0}$ & $3,421.69$ & $4,194.95$ & $4,548.76$ \\
\hline & \multirow{5}{*}{$G=26$} & $\lambda_{0}$ & 1.202780 & 1.324044 & 1.406468 \\
\hline & & $s$ & 0.168593 & 0.244738 & 0.288999 \\
\hline & & $G_{\min }$ & 21.616583 & 19.636810 & 18.486024 \\
\hline & & $\begin{array}{l}\text { Est. } \\
\text { Dis. }\end{array}$ & $\begin{array}{c}{[303.4,188.3,149.1,122.5} \\
100.4,79.0,43.6]\end{array}$ & $\begin{array}{c}{[666.3,355.0,238.2,161.4} \\
104.2,59.2,20.4]\end{array}$ & $\begin{array}{c}{[973.6,473.1,287.6,174.1,} \\
98.3,46.9,12.9]\end{array}$ \\
\hline & & $N P V_{0}$ & 3635.05 & 4477.23 & 4866.59 \\
\hline
\end{tabular}

The $N P V$ values corresponding to the "sustainable/stable" harvesting strategies are:

$$
N P V=\sum_{k=1}^{n} \sum_{t=0}^{T-10} w_{k} \cdot s \cdot v_{k}(t) \frac{1}{(1+i)^{t}}+\sum_{k=1}^{n} w_{k} \cdot v_{k}(T) \frac{1}{(1+i)^{T}}
$$

Since the optimal harvesting strategies produced by the solutions of the discrete optimal control problem described in Section 2.2 could give rise to diameter distributions $(X)$ that differ from the stable $\left(W_{0}\right)$, we evaluated the distance between these distributions with Keyfitz's $\Delta$ :

$$
\Delta\left(X, W_{0}\right)=\frac{1}{2} \sum_{i=1}^{n}\left|x_{i}-w_{i}\right|
$$

where $x_{i}$ and $w_{i}$ are the components of the diameter distributions $X$ and $W_{0}$, scaled to one [30]:

$$
\text { (i.e., } \sum_{i=1}^{n} x_{i}=\sum_{i=1}^{n} w_{i}=1 \text { ). }
$$


The maximum value of $\Delta$ is one, and the minimum of zero occurs when the diameter distributions, $X$ and $W_{0}$ (scaled to one), are identical. Smaller values of $\Delta$ result when the distributions, $X$ and $W_{0}$ (scaled to one), become more similar.

\subsubsection{Stumpage Value Model}

The stumpage value model applied in this study is a generalization of the model proposed for Quality I in [14] for Pinus nigra in the Spanish Iberian System. In Table 3, we provide the stumpage prices we used in the objective function. Industrial destinations and diameter classes considered are based on those used in previous studies [27,31]. The regression models adjusted to these data appear in Figure 2. The prices in Table 3 come from the official statistics [32] and have been contrasted with real data from actual harvests. The stumpage prices of Pinus nigra in Spain have remained fairly stable between 1994 and 2011 [32].

Table 3. Stumpage prices $\left(€ / \mathrm{m}^{3}\right)$ of Pinus nigra in Spain according to diameter class and contribution to the final price of the four industrial destinations considered.

\begin{tabular}{cccc}
\hline Products & \multicolumn{3}{c}{ Diameter classes $(\mathrm{cm})$} \\
\cline { 2 - 4 } Particle board & $<20$ & $20-40$ & $>40$ \\
Poles & 6 & 1.2 & 0.6 \\
Sawlog & 0 & 11.85 & 0 \\
High quality sawlog & 0 & 9.8 & 11.76 \\
Total average price & 0 & 0 & 9.96 \\
\hline
\end{tabular}

Figure 2. Stumpage price models: Quality I, $v=D^{3.186471} \exp \left(-7.704952-8.678687 \cdot 10^{-3}\right.$ $D)$; Quality II, $v=D^{3.114196} \exp \left(-7.476506-9.903125 \cdot 10^{-3} D\right)$; and Quality III: $v=D^{2.987053} \exp \left(-7.110977-1.078752 \cdot 10^{-2} D\right)$ (stumpage prices $v$ in euro stem ${ }^{-1}$ and diameter $D$ in $\mathrm{cm}$ ). The coefficient of determination was always greater than 0.9999 .

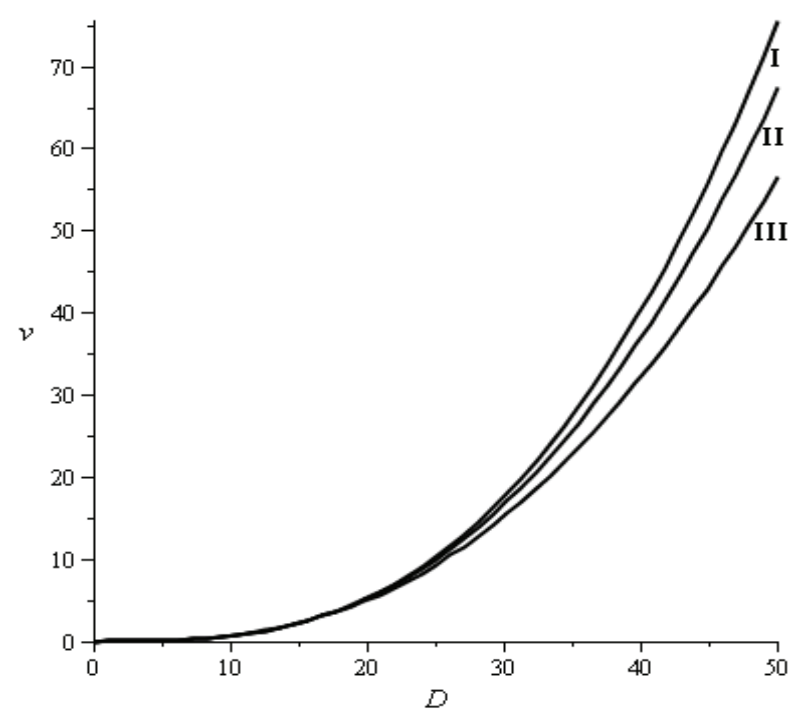


The last row in Table 3 shows average price per cubic meter for trees belonging to the different diameter classes. This price is obtained by adding up the four rows above showing the contributions to the final value of a tree of the four industrial destinations according to the percentage of wood of each diameter class going into each product type. The prices of particle board, poles, sawlog and high quality sawlog are $6.0,39.5,19.6$ and $33.2 € / \mathrm{m}^{3}$, respectively.

\section{Results and Discussion}

\subsection{Results}

By substituting the transition probabilities in Table 1, the "sustainable/stable" harvest rates, $s$, and stable diameter distributions, $W_{0}$, in Table 2 , into the proposed discrete optimal control model and solving globally the corresponding optimization problems (Solver finds the globally optimal solution to each problem by changing the $h_{k}(t)$ variables, for $k=1,2, \ldots, n$, and $t=0,10,20, \ldots, 70$ years), we obtained optimal state and control variables, $x_{k}(t)$ and $h_{k}(t)$; basal areas before and after each harvest; optimal $N P V$ and the $N P V$ corresponding to the "sustainable/stable" harvesting strategy; and Keyfitz's $\Delta$ for all the scenarios. The discount rates applied fell between $2 \%-6 \%$, as is typical of forest management studies.

We thus obtain four main results. First, Figure 3 shows the population dynamics, $x_{k}$, needed to maximize the $N P V$ function over 70 years with $G=24 \mathrm{~m}^{2} \mathrm{ha}^{-1}$ and $i=3 \%$. Second, Figure 4 depicts the optimal harvesting strategies, $h_{k}(t)$, for $G=24 \mathrm{~m}^{2} \mathrm{ha}^{-1}$ and $i=3 \%$. Third, the $N P V$ increase between the "sustainable/stable" harvesting strategy $s$ and the optimal harvesting strategy (maximizing $N P V$ function) for $i=3 \%$ and different values of Quality, $R$ and $G$, appears in Table 4. Fourth, Table 5 shows the set of values for Keyfitz's $\Delta$ at the end of the harvest cycle, along with the population growth rate, $\lambda_{T}$, for the whole harvest cycle of $T=70$ years. Note that the transition matrix, $A_{T}$, for the whole harvest cycle (from $t=0$ to $t=70$ years) is:

$$
A_{T}=\prod_{t=T-10}^{t=0} A(I-H(t)),
$$

and that $\lambda_{T}<1$ for all the scenarios. Therefore, the economically optimal harvesting strategies were unsustainable for all the scenarios, which implies that, by executing the same harvest cycle indefinitely, the population of trees would be decaying until extinction.

The tables and figures mentioned in the above paragraph are included below.

The optimal harvesting strategy, designed to maximize $N P V$, results in higher $N P V$ figures than the "sustainable/stable" strategy. For $i=3 \%$, this increment is always greater than $8.43 \%$, with a maximum of $17.50 \%$ for Quality I, $R=520 \mathrm{stems} / \mathrm{ha}$ and $G=22 \mathrm{~m}^{2} /$ ha. The $N P V$ increase was greater for Quality I than for Quality II or Quality III. For higher discount rates, $N P V$ increase rates are slightly higher, from a minimum of $10.88 \%$ to a maximum of $21.29 \%$ for $i=6 \%$, Quality I, $\mathrm{R}=520 \mathrm{stems} / \mathrm{ha}$ and $\mathrm{G}=24 \mathrm{~m}^{2} /$ ha. The pattern of change for the three site qualities is kept for the different discount rates. 
Figure 3. Population dynamics, $x_{k}$, to maximize the $N P V$ function throughout a harvest cycle of 70 years for $G=24 \mathrm{~m}^{2} \mathrm{ha}^{-1}$ and $i=3 \%$ (left: Quality I; middle: Quality II; right: Quality III; first row: $R=200$ stems/ha; second row: $R=520$ stems/ha; third row: $R=840$ stems/ha). The initial conditions (intercepts on ordinate axis) are defined by the stable diameter distributions.
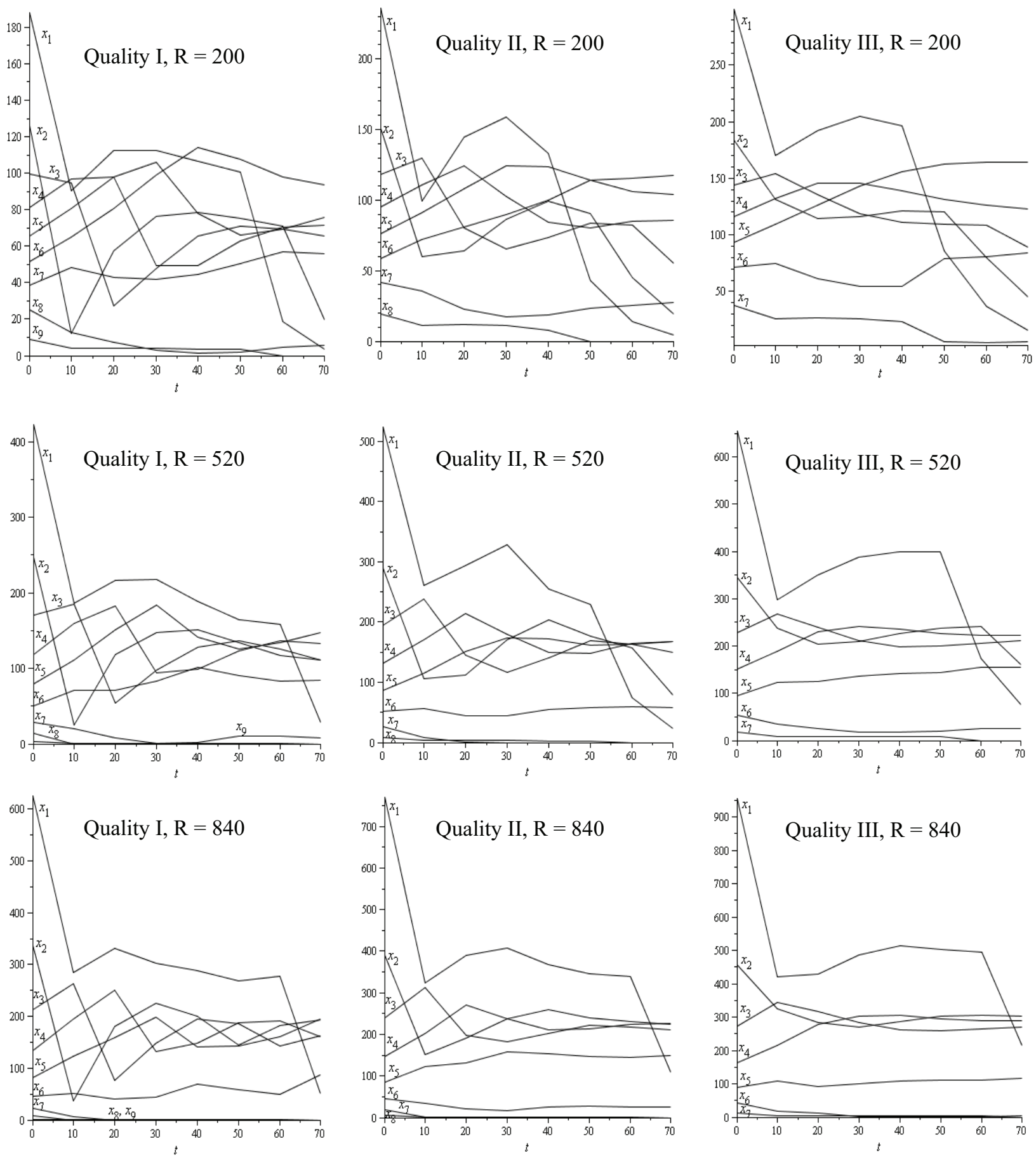
Figure 4. Optimal harvesting strategies, $h_{k}(t)$, for $G=24 \mathrm{~m}^{2} \mathrm{ha}^{-1}$ and $i=3 \%$ (left: Quality I; middle: Quality II; right: Quality III; first row: $R=200$ stems/ha; second row: $R=520 \mathrm{stems} / \mathrm{ha}$; third row: $R=840 \mathrm{stems} / \mathrm{ha})$. The dashed lines depict the "sustainable/stable" harvest rates, $s$.

Quality I, R = 200

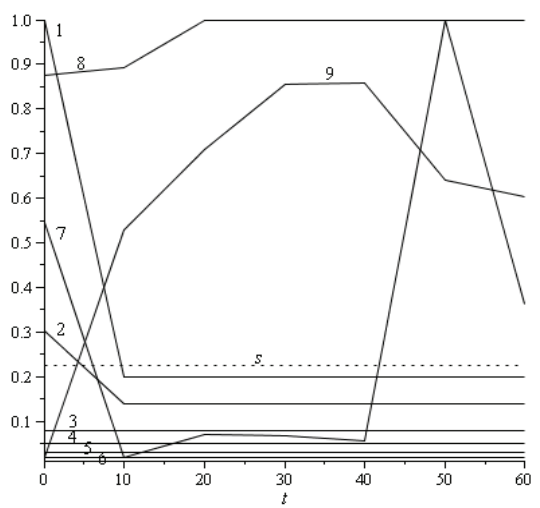

Quality I, R = 520

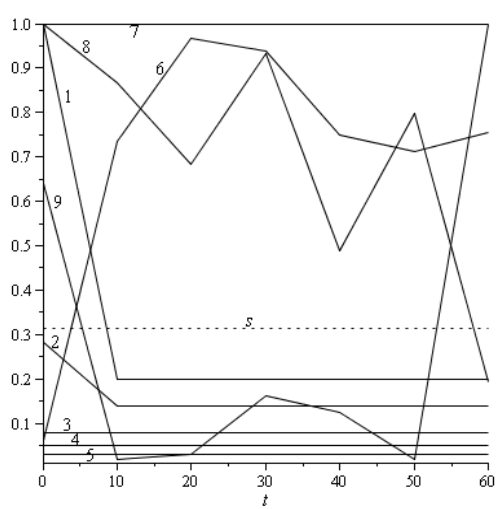

Quality I, R = 840

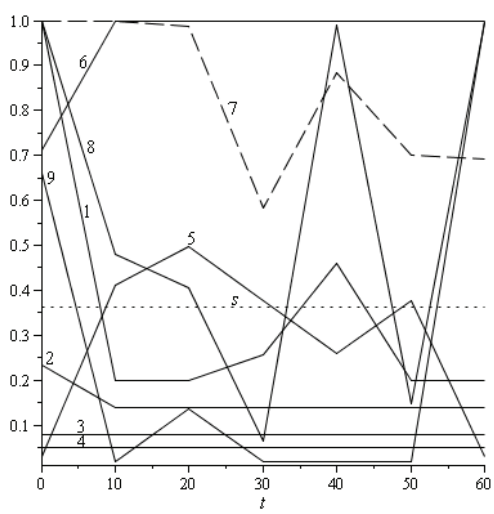

Quality II, R = 200

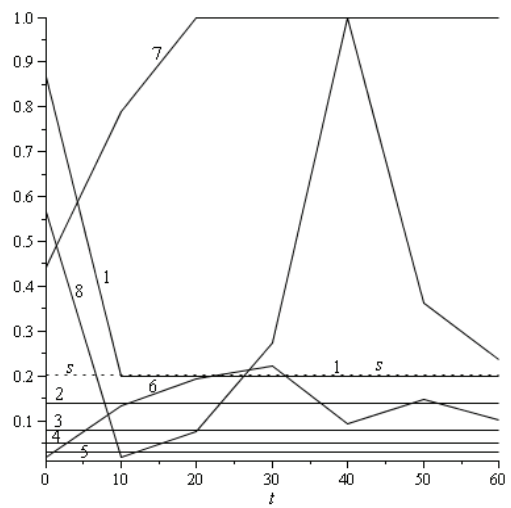

Quality II, R = 520

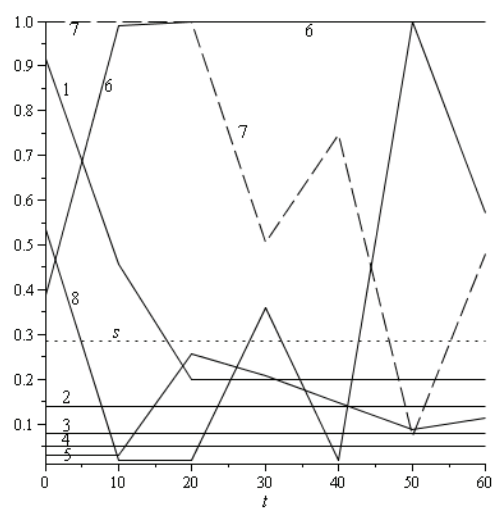

Quality II, R = 840

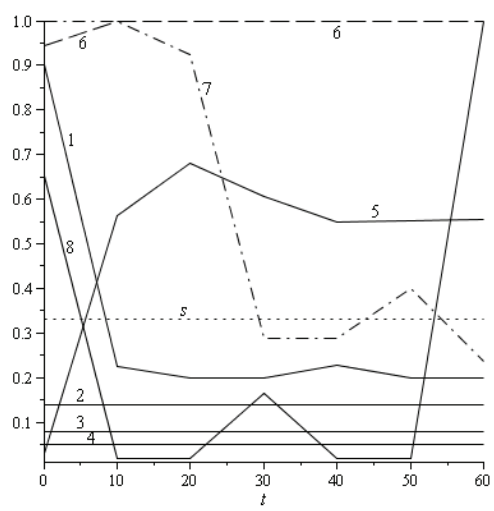

Quality III, R = 200

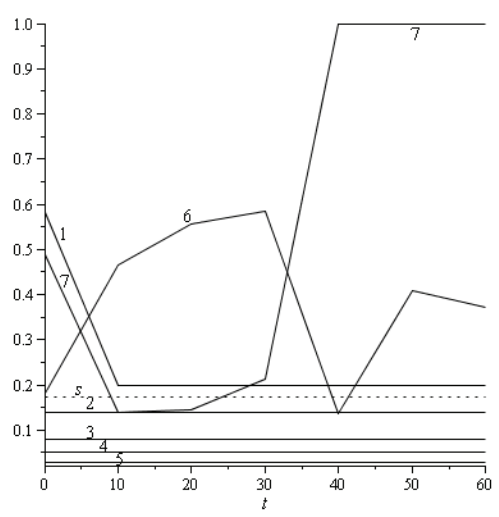

Quality III, R = 520

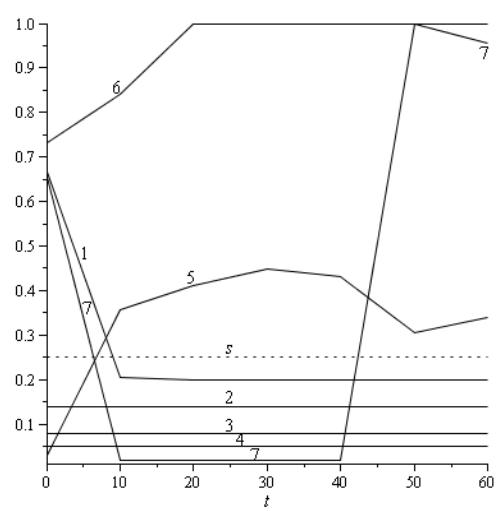

Quality III, R = 840

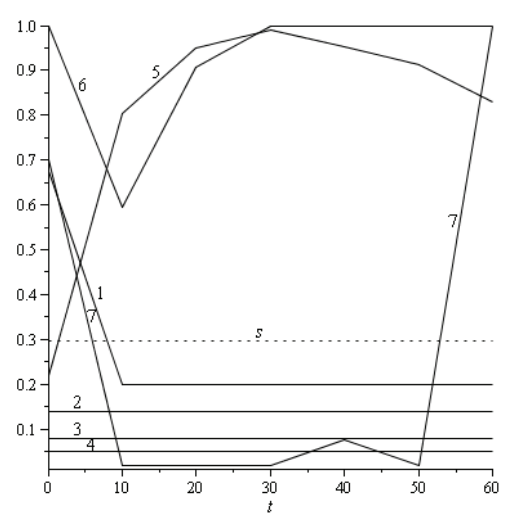


Table 4. Optimal strategy $N P V$ and $N P V$ increase (\%) between the optimal and "sustainable/stable" harvesting strategies for $i=3 \%$ and different levels of Quality, $R$ and $G\left(G\right.$ in $\left.\mathrm{m}^{2} / \mathrm{ha}\right)$.

\begin{tabular}{|c|c|c|c|c|c|c|c|}
\hline & & \multicolumn{2}{|c|}{$R=200$ stem $/$ ha } & \multicolumn{2}{|c|}{$R=520$ stem $/$ ha } & \multicolumn{2}{|c|}{$R=840$ stem $/$ ha } \\
\hline & & $\begin{array}{l}N P V \\
(€ / \mathrm{ha})\end{array}$ & $\begin{array}{c}N P V \\
\text { increase } \\
(\%)\end{array}$ & $\begin{array}{l}N P V \\
(€ / \mathrm{ha})\end{array}$ & $\begin{array}{c}N P V \\
\text { increase } \\
(\%)\end{array}$ & $\begin{array}{l}N P V \\
(€ / \mathrm{ha})\end{array}$ & $\begin{array}{c}N P V \\
\text { increase } \\
(\%)\end{array}$ \\
\hline \multirow{3}{*}{ Q I } & $G=22$ & 6205.07 & 16.04 & 7188.49 & 17.50 & 7468.18 & 17.00 \\
\hline & $G=24$ & 6636.65 & 15.55 & 7767.29 & 17.49 & 8095.43 & 17.00 \\
\hline & $G=26$ & 7056.80 & 15.11 & 8316.44 & 17.19 & 8718.00 & 17.06 \\
\hline \multirow{3}{*}{ Q II } & $G=22$ & 4788.21 & 12.95 & 5754.83 & 15.40 & 6139.05 & 16.18 \\
\hline & $G=24$ & 5124.07 & 12.80 & 6203.83 & 15.44 & 6623.80 & 15.99 \\
\hline & $G=26$ & 5453.96 & 12.71 & 6647.77 & 15.53 & 7098.14 & 15.77 \\
\hline \multirow{3}{*}{ Q III } & $G=22$ & $3,502.94$ & 9.38 & $4,389.27$ & 12.36 & $4,820.65$ & 14.10 \\
\hline & $G=24$ & $3,724.85$ & 8.86 & $4,701.48$ & 12.07 & $5,185.97$ & 14.00 \\
\hline & $G=26$ & $3,941.58$ & 8.43 & $5,007.24$ & 11.84 & $5,529.35$ & 13.62 \\
\hline
\end{tabular}

Table 5. Keyfitz's $\Delta$ values, corresponding to the distance between the diameter distribution associated with the optimal harvesting strategy (for $t=70$ years) and the stable diameter distribution $\left(W_{0}\right)$, as well as population growth rates, $\lambda_{T}$, for the whole harvest cycle (from $t=0$ to $t=70$ years) $\left(G\right.$ in $\mathrm{m}^{2} / \mathrm{ha}$ ).

\begin{tabular}{cccccccc}
\hline & & \multicolumn{2}{c}{$\mathbf{R}=\mathbf{2 0 0}$ stem $/ \mathbf{h a}$} & \multicolumn{2}{c}{$\mathbf{R}=\mathbf{5 2 0}$ stem/ha } & \multicolumn{2}{c}{$\mathbf{R}=\mathbf{8 4 0}$ stem $/ \mathbf{h a}$} \\
\hline \multirow{4}{*}{ Q I } & & $\Delta$ & $\lambda_{T}$ & $\Delta$ & $\lambda_{\mathrm{T}}$ & $\Delta$ & $\lambda_{T}$ \\
& $\mathrm{G}=22$ & 0.450415 & 0.056033 & 0.397311 & 0.002602 & 0.394624 & 0.000226 \\
& $\mathrm{G}=24$ & 0.434304 & 0.178754 & 0.392813 & 0.002866 & 0.390207 & 0.000284 \\
& $\mathrm{G}=26$ & 0.425244 & 0.210573 & 0.437235 & 0.002866 & 0.387282 & 0.000559 \\
& $\mathrm{G}=22$ & 0.467745 & 0.310556 & 0.490225 & 0.006628 & 0.361989 & 0.004161 \\
QII & $\mathrm{G}=24$ & 0.467935 & 0.333705 & 0.487651 & 0.011089 & 0.351967 & 0.004161 \\
& $\mathrm{G}=26$ & 0.468382 & 0.354182 & 0.478031 & 0.014921 & 0.346997 & 0.004161 \\
& $\mathrm{G}=22$ & 0.348297 & 0.604092 & 0.392534 & 0.275817 & 0.335904 & 0.365103 \\
Q III & $\mathrm{G}=24$ & 0.422880 & 0.551102 & 0.385367 & 0.303478 & 0.323309 & 0.336591 \\
& $\mathrm{G}=26$ & 0.417756 & 0.562400 & 0.378934 & 0.337522 & 0.324559 & 0.312709 \\
\hline
\end{tabular}

Applying the optimal harvesting strategy, for Qualities I, II and III, the diameter distribution of the stand evolved through time, leaving the initial equilibrium distribution and tending toward a diameter distribution more characteristic of even-aged stands. For high recruitments ( $R=840$ stems/ha), the resulting distribution at the end of $T=70$ years is a bimodal distribution, more accentuated for Quality I. Figure 5 contains, as an example, a scenario corresponding to Quality I, $G=24 \mathrm{~m}^{2} / \mathrm{ha}, R=$ 520 stems $/$ ha and $i=3 \%$. 
Figure 5. Evolution of the diameter distribution with the economically optimal harvesting strategy throughout a harvest cycle of 70 years for Quality I, $G=24 \mathrm{~m}^{2} / \mathrm{ha}$, $R=520 \mathrm{stems} /$ ha and $i=3 \%$.

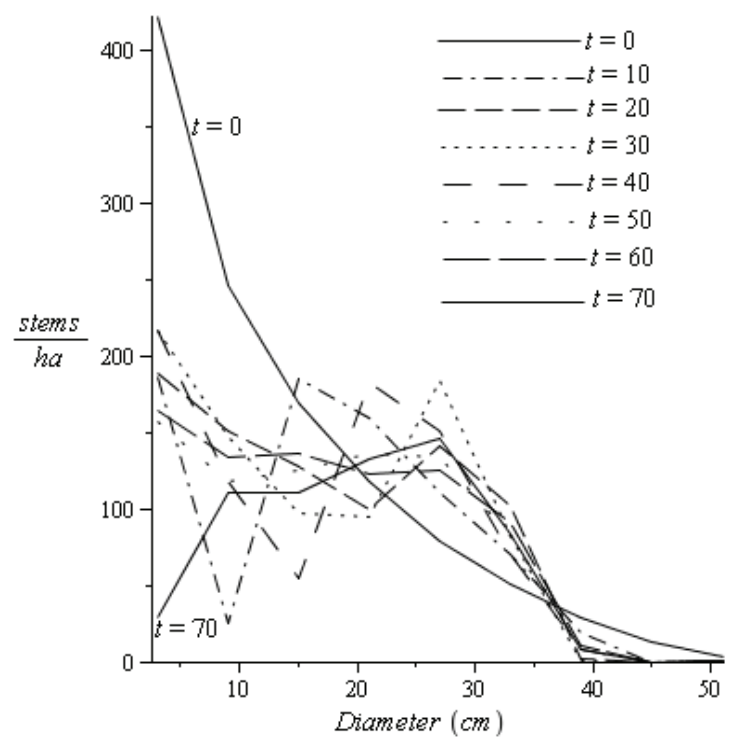

The influence of small variations in the discount rate or the natural mortality rates on the optimal harvesting strategies was minimal, because they did not change the general pattern of the solutions.

\subsection{Discussion and Conclusions}

This study proposes a model that combines an objective function comprising the $N P V$ of all the management operations in a planning horizon of 70 years with a matrix model for the population dynamics. The resulting discrete optimal control model provides a simple tool for heuristic analysis to answer the "what if" questions in relation to forest management actions.

Following López et al. [7-9], we calculated the transition probabilities considering that $p_{k}$ is an average global property shared by all the individuals in the same class $k$, and that, given the basal area constraints and the low basal area scenarios of this study, there is a low variability around the mean $p_{k}$ values (see section 2.3.1) thus resulting in a small influence on diameter growth. Moreover, in the case of these constrained optimization matrix models, in which the search for optimal paths throughout the phase space is mainly governed by the objective function, optimal decisions are essentially conditioned by the stumpage prices, i.e. by selective harvesting, and thus stand density has minor influence on the objective.

López et al. [8] also show that results obtained for $\lambda_{0}$ are sensitive to the width, $w$, of the diameter classes, such that the most conservative values of $\lambda_{0}$ and $s$ result from the lowest values of $w$ (which does not allow an individual tree to jump over more than one diameter class in a single projection). The minimum (integer) widths of the diameter classes compatible with this model assumption were $w=6 \mathrm{~cm}$ for Quality I, $w=5 \mathrm{~cm}$ for Quality II and $w=4 \mathrm{~cm}$ for Quality III. However, since the dominant eigenvalue $\lambda_{0}$ and the stable diameter distribution are not substantially affected by small or even moderate changes in the width of the diameter classes, the width considered throughout this study was $w=6 \mathrm{~cm}$, to facilitate the comparison of results. 
The basal area indirectly resulted in optimization problems, such as a "bang-bang control" variable, which oscillated between $G_{\min }$ and $G_{\max }$. The upper and lower bounds imposed on basal area values are derived from the "sustainable/stable" harvesting strategy (to compare the optimal strategy with the "sustainable/stable").

By applying optimal harvesting strategies, the schedules aim for the highest $N P V$, with an intense harvest $(h>0.5)$ performed in the diameter classes during the planning horizon as follows:

For high recruitments, the intense harvest applies to the upper diameter class at the beginning (first period) and the end (seventh period) of the planning horizon. In addition, for medium and high recruitments, the intense harvest gets performed in every period of the planning horizon for the diameter classes corresponding to poles, while low recruitments follow a different pattern. In this case, the intense harvest is performed in the upper diameter classes, since low recruitments are associated with a lower number of stems per hectare with a higher average diameter.

For the three qualities, this harvest pattern caused a decrease in the number of stems of the first diameter class, such that at the end of the time horizon, the diameter range of the distribution narrowed and shifted from a reversed J-shaped curve to a bell-shaped curve, centered on the medium diameter classes $(18-36 \mathrm{~cm})$, as is typical of an even-aged stand distribution (see Figure 5). The intermediate diameter classes correspond to trees going to the production of poles. This type of evolution might be favored by market conditions for Pinus nigra products in Spain, because of the high price of poles obtained from those diameter classes (see Table 3).

There is not a significant change in the harvest pattern for the optimal strategy when higher discount rates are considered, except for a slight trend to advance harvest in the upper diameter classes. This result, leading to an earlier harvest, is consistent with an increase in the discount rate.

The NPV increase rate between the optimal and "sustainable/stable" harvesting strategies grows slightly with discount rate. The pattern of $N P V$ change for the three site qualities is kept for the different discount rates considered in the analysis.

By applying the optimal harvesting strategies, at the end of $T=70$ years, the Keyfitz's $\Delta$ values ranged from 0.32 to 0.49 ; that is, the stand moved away from the equilibrium. For $i=3 \%$, the lowest $\Delta$ values emerged for higher recruitments ( $R=840$ stems/ha) and Quality III.

Regarding the sustainability of the optimal harvesting strategies, all the scenarios were unsustainable (see Table 5). In fact, the population growth rate, $\lambda_{T}$, for the whole harvest cycle (given by the dominant eigenvalue of the transition matrix, $A_{T}$ ) was always $\lambda_{T}<1$. Moreover, the population decline was greater for Quality I, followed by Quality II and Quality III, and with some exceptions, the greater the recruitment was, the greater the population decline induced by the optimal harvesting strategies. It is not difficult to implement constraints to obtain $\lambda=1$ at each time step (for example, by assuming in the model a new set of constraints obtained by solving the determinant $\operatorname{det}(A(I-H(t))-I)=0$ for $h_{n}(t)$, at each time step), but this does not guarantee either that $\lambda_{T}=1$ or that the stable distribution is reached at $t=T$ (the $\lambda_{T}$ values are in this case closer to one, but clearly, it remains $\lambda_{T}<1$ for all the scenarios). However, with the "sustainable/stable" harvesting strategy, we get $\lambda=1$ and the stable diameter distribution at each time step, and $\lambda_{T}=1$ for the whole harvest cycle.

In conclusion, the proposed discrete optimal control model was used to analyze if the introduction of an NPV maximizing management strategy on the dynamics of uneven-aged Pinus nigra stands in demographic equilibrium (with the stable diameter distribution $W_{0}$ set as the initial condition), leads to 
distributions that move away from that equilibrium through time and assessing the sustainability of those strategies. Our results suggest that the economically optimal harvesting strategies were unsustainable and unstabilizing for all the scenarios. This is unsurprising, because these assumptions $\left(\lambda_{T}=1\right.$ and $\left.W_{0}\right)$ were not specified in the model. In addition, these considerations in general are not present in previous models to optimize uneven-aged stands management. Therefore, it would be interesting to incorporate into further evolutions of this optimization model constraints related to the maintenance of a certain age structure, a final stable distribution (i.e., $X(T)=W_{0}$ ) and/or the sustainability for the whole harvest cycle $\left(\lambda_{T}=1\right)$. These determinants are common in traditional uneven-aged forest management.

\section{Conflicts of Interest}

The authors declare no conflict of interest.

\section{References}

1. Buongiorno, J.; Michie, B.R. A matrix model of uneven-aged forest management. For. Sci. 1980, $26,609-625$.

2. Caswell, H. Matrix Population Models: Construction, Analysis, and Interpretation, 2nd ed.; Sinauer Associates Inc.: Sunderland, MA, USA, 2001; p. 713.

3. Picard, N.; Ouédraogo, D.; Bar-Hen, A. Choosing classes for size projection matrix models. Ecol. Model 2010, 221, 2270-2279.

4. Escalante, E.; Pando, V.; Ordoñez, C.; Bravo, F. Multinomial logit estimation of a diameter growth matrix model of two Mediterranean pine species in Spain. Ann. For. Sci. 2011, 68, 715-726.

5. Gotelli, N.J. A Primer of Ecology; Sinauer Associates Inc.: Sunderland, MA, USA, 2001; p. 265.

6. Schütz, J.P. Modelling the demographic sustainability of pure beech plenter forests in Eastern Germany. Ann. For. Sci. 2006, 63, 93-100.

7. López, I.; Ortuño, S.F.; Martín, A.J.; Fullana, C. Estimating the sustainable harvesting and the stable diameter distribution of European beech with projection matrix models. Ann. For. Sci. 2007, 64, 593-599.

8. López, I.; Fullana, C.; Ortuño, S.F.; Martín, A.J. Choosing Fagus sylvatica L. matrix model dimension by sensitivity analysis of the population growth rate with respect to the width of the diameter classes. Ecol. Model 2008, 218, 307-314.

9. López, I.; Ortuño, S.; García, F.; Fullana, C. Is De Liocourt's distribution stable? Forest Sci. 2012, $58,34-46$.

10. Haight, R.G. A comparison of dynamic and static economic models of uneven-aged stand management. Forest Sci. 1985, 31, 957-974.

11. Sethi, S.P.; Thompson, G.L. Optimal Control Theory: Applications to Management Science and Economics, 2nd ed.; Kluwer Academic Publishers: Dordrecht, The Netherlands, 2000. 
12. Kronrad, G.D.; Huang, C.H. Financially optimal thinning and final harvest schedules for loblolly pine plantations on nonindustrial private forestland in east Texas. South J. Appl. For. 2002, 26, $13-17$.

13. Tahvonen, O. Optimal harvesting of forest age classes: A survey of some recent results. Math Popul. Stud. 2004, 11, 205-232.

14. López, I.; Ortuño, S.; Martín, A.J.; Fullana, C. Estimating the optimal rotation age of Pinus nigra in the Spanish Iberian System applying discrete optimal control. For. Syst. 2010, 19, 306-314.

15. Maple, Version 16.0; Maplesoft: Ontario, Canada, 2012.

16. Front Line Systems Solver Premium Platform. Incline Village, NV, USA, 2008. Available online: http://www.solver.com (accessed on 26 July 2013).

17. Grande, M.A.; García Abril, A. Los Pinares de Pinus nigra Arn. en España: Ecología, uso y gestión; Fundación Conde del Valle de Salazar (FUCOVASA): Madrid, Spain, 2005; pp. 1-53.

18. Gómez Loranca, J.A. Modelo de crecimiento y producción para Pinus nigra Arn. en el Sistema Ibérico. Revista Montes 1998, 54, 5-18.

19. Siegel, W.; Hoover, W.; Haney, H.; Liu, K. Forest Owners' Guide to the Federal Income Tax; Agriculture Handbook No. 708; United States Department of Agriculture, Forest Service: Washington, DC, USA, 1995; p. 138.

20. Retana, J.; Espelta, J.M.; Habrouk, A.; Ordóñez, J.L.; Solà-Morales, F. Regeneration patterns of three Mediterranean pines and forest changes after a large wildfire in north-eastern Spain. Ecoscience 2002, 9, 89-97.

21. Tíscar, P.A. Dinámica de regeneración de Pinus nigra subs. Salzmannii al sur de su área de distribución: etapas, procesos y factores implicados. Inv. Agrar. Sist. Rec. F. 2007, 16, 124-135.

22. Tíscar Oliver, P.A.; Lucas, M.E.; Tíscar Soria, M.A. La alteración del suelo y la espesura como factores de regeneración de Pinus nigra subs. Salzmannii a lo largo de su área de distribución. Revista Montes 2010, 103, 10-15.

23. Schütz, J.P. Le régime du jardinage. Document autographique du cours de Sylviculture III; Chaire de Sylviculture; E.T.H. Zürich: Zürich, Switzerland, 1989; p. 55.

24. Serrada, R.; Domínguez Lerena, S.; Sánchez Resco, M.I.; Ruiz Ortiz, J. El problema de la regeneración natural de Pinus nigra Arn. Revista Montes 1994, 36, 52-57.

25. Van Mantgem, P.J.; Stephenson, N.T. The accuracy of matrix population model projections for coniferous trees in the Sierra Nevada, California. J. Ecol. 2005, 93, 737-747.

26. Misir, M.; Misir, N.; Yavuz, H. Modeling individual tree mortality for Crimean pine plantations. $J$. Environ. Biol. 2007, 28, 167-172.

27. Trasobares, A.; Pukkala, T. Optimising the management of uneven-aged Pinus sylvestris L. and Pinus nigra Arn. mixed stands in Catalonia, north-east Spain. Ann. For. Sci. 2004, 61, 747-758.

28. Ramula, S.; Lehtilä, K. Matrix dimensionality in demographic analyses of plants: When to use smaller matrices? Oikos 2005, 111, 563-573.

29. Zuidema, P.A. Demography of Exploited Tree Species in the Bolivian Amazon; PROMAB Scientific Series 2; Promab: Riberalta, Bolivia, 2000; p. 240.

30. Keyfitz, N. Introduction to the Mathematics of Population; Addison-Wesley: Reading, MA, USA, 1968; p. 464. 
31. Montero, G.; Rojo, A.; Alía, R. Determinación del turno de Pinus sylvestris L en el Sistema Central. Revista Montes 1992, 29, 42-47.

32. Boletín Mensual de Estadística 1994-2011; Ministerio de Agricultura, Alimentación y Medio Ambiente: Madrid, Spain, 2011; pp. 29-33.

(C) 2013 by the authors; licensee MDPI, Basel, Switzerland. This article is an open access article distributed under the terms and conditions of the Creative Commons Attribution license (http://creativecommons.org/licenses/by/3.0/). 